\title{
BURDEN OF PROOF IN DIALOGUE GAMES AND DUTCH CIVIL PROCEDURE
}

\author{
Ronald E. Leenes \\ Faculty of Public Administration and Public Policy, University of Twente \\ P.O. Box 217, 7500 AE Enschede, the Netherlands \\ r.e.leenes@bsk.utwente.nl
}

\begin{abstract}
In recent years dialectics has become popular in Artificial Intelligence and law. A sub-branch of this field concentrates on the development of dialogue games. Many of these legal dialogue systems are fairly simple, in some respects even too simple. Among the topics dialogue games can improve on, is the division of the burden of proof. In this paper I discuss some legal dialogue games in the light of an actual legal procedure to show the shortcomings of these models. The paper shows what computational dialectics can learn form legal practice.
\end{abstract}

\section{INTRODUCTION}

In recent years, argument and dialogue have received considerable interest in AI and law research [6, 2, 3, 13, 16, 15]. In legal domains everything, including the rules, is subject to debate. This fact makes the study of argument itself of interest. Legal argument may be convincing although unsound in terms of logic, and unpersuasive, although sound [2]. To understand legal argument we have to look at the rhetorical, procedural and contextual aspects of the process instead of just the logical features of legal reasoning.

One strand in the study of legal argument in AI is concerned with the construction of dialogue games. Many of these legal dialogue games are inspired by the notion of procedural justice $[18,1]$. The dialogue in a dialogue system is governed by rules that are to ensure the rights and obligations of the participants in the dialogue. At the same time the rules are to guarantee that the parties stay within the bounds of the law. An arbiter (a judge or court, for instance) sees to it that the dialogue in fact remains within these bounds. The arbiter, the dialogue rules and the law, together, prevent the parties to decide anything they want and keep them within a problem space in which the outcomes are all legally correct.

Permission to make digital or hard copies of all or part of this work for personal or classroom use is granted without fee provided that copies are not made or distributed for profit or commercial advantage and that copies bear this notice and the full citation on the first page. To copy otherwise, or republish, to post on servers or to redistribute to lists, requires prior specific permission and/or a fee.

ICAIL-2001, St. Louis, Missouri USA.

Copyright 2001 ACM 1-58113-368-5/01/0005 \$5.00.
Dialogue games can be seen as a test to see whether constraints on procedural justice can be monitored or checked by purely formal methods. In this respect the dialogue rules implemented in the dialogue game, are important. They determine the 'look and feel' of the game, but also its fitness for use as a model of legal dialogues.

An important group of discourse rules deals with the allocation of the burden of proof. A player in a dialogue game advances claims, some of which will be disputed by the opposing player. Each player has to have the option of questioning claims brought forward by the other player. If a claim is questioned, the proponent has to provide a backing or justification for the disputed claim. This rule is essential for rational discourse [1]. However, it also carries a risk: if the opponent constantly replies by asking for more justification by the proponent, the dialogue could result in an infinite regress. Somewhere along the line the justification should be sufficient. The rules pertaining to the burden of proof play an important role in regulating the justification process.

Every dialogue game incorporates rules on the burden of proof for statements. Often, a simple rule such as "Whoever advances a standpoint is obliged to defend it if asked to do so" is used. Lodder [13] for instance, uses this rule for the distribution of burden of proof in his DiaLaw. Alexy [1], uses a slightly more complex rule in his theory of rational discourse. He adds that no burden of proof exists if reasons which justify a refusal to provide a justification can be given.

Both Alexy and Lodder claim their model to be universal and not tailored to a specific type of legal discourse. It has been argued [6] that the discourse norms should depend on the nature and purpose of a particular type of legal proceedings. This paper deals with the burden of proof from the perspective of a particular type of legal proceedings, the Dutch Civil Summons Procedure. I will show that burden of proof in a specific type of legal procedure is more complex than accounted for in current dialogue systems. My point of departure for the study of burden of proof in dialogue games is legal practice.

The rest of the paper is structured as follows. In section 2 I discuss the burden of proof in three well known dialogue systems: Arno Lodder's DiaLaw, Trevor Bench-Capon's Toulmin Dialogue Game and Tom Gordon's Pleadings Game. In section 3 I describe the Dutch civil summons procedure and the way the burden of proof is handled within this procedure. Section 4 offers a brief 
discussion of the shortcomings of the dialogue systems discussed. Section 5 concludes the paper with suggestions for further research.

\section{DIALOGUE GAMES}

\subsection{Burden of Proof}

If a party in a dialogue introduces a statement the truth value of this statement is unknown. The proponent claims the statement to be true. If the other player accepts the statement, there is no problem: both players become committed to the statement ending the dispute even before it started. ${ }^{1}$ But if the opponent does not accept the statement, there is indeed a problem: should we accept the statement to be true or false. This is where the burden of proof (or burden of justification) comes in. It is a way of making a default decision about the presence of facts. Some facts are assumed (not) to obtain, unless the party that has the burden of proof proves otherwise [10]. Therefore the speaker who asserts a certain statement must be prepared to prove this statement, for instance by means of supporting arguments. In real legal procedures, the role of allocating the burden over the adversaries is an important task of the arbiter (and the discourse rules) [17]. In dialogue games there often is no arbiter, hence the discourse rules are all the more important. They are necessary to guide the dialogue.

Related to the concept of burden of proof is the concept of commitment. Parties in a dialogue are generally committed to what they state in the dialogue. They should respect these commitments during the rest of the dialogue. This, for instance, means they may not question a statement to which they are committed later on in the dialogue. As Prakken [17] points out, commitments are about being coherent. The burden of proof is about being right. Parties may be requested, either by the discourse rules or by the judge to provide reasons that underpin the truth of a claim. Having the burden of proof is independent of being committed [17]. This is especially so in actual legal procedures because the judge may assign the burden of proof to any of the adversaries. Suppose the plaintiff claims $p$ and the defendant challenges $\mathrm{p}$. The judge may then assign the burden to prove $-p$ to the defendant. The defendant is not committed to $-p$ by merely challenging $\mathrm{p}$. We will see examples of this kind of burden of proof assignments in actual practice later on.

There is another aspect of the burden of proof that is important for our purposes. Prakken [16] points out that having the burden of proof for a claim means one has the obligation to come up with an argument for that claim, and the obligation to uphold this argument against challenge in a dialogue. But how strong should the challenge be in order to defeat an argument? In many dialogue games there is a dialectical asymmetry [17]. The proponent wants his initial claim justified. His attacks must be stronger than their targets (strict defeat). The opponent has an

\footnotetext{
${ }^{1}$ In pure procedures it is irrelevant whether the statement is true in the real world; the parties involved in the procedure determine the facts. I come back to this topic in paragraph 3.2.
}

easier task. She only has to cast sufficient doubt on the proponent's claim (defeat) to prevent the proponent from meeting his aim. However, as Prakken argues in $[16,17]$ and as we will see in section 4 , there may be shifts in dialectical roles depending on whether arguments are given to meet a burden of proof, or to prevent a burden of proof to be met.

The dialectical asymmetry that places a stronger burden on the party that wants to uphold the initial claim is an important aspect of a dialogue. The shifts in dialectical roles also have to be accommodated correctly, otherwise the burden would rest on the wrong shoulders, which is undesirable. Especially because the proof burden may be used as an instrument to frustrate the dialogue. Proof may fail and the player who has to prove or justify certain facts has to allocate (valuable) resources to accomplish the proof. The players will therefore try to escape their burden by presenting suitable moves, providing the least possible support for their claims if they bear burden of proof. If the burden rests with the other party, asking for more justification is a way to stall the dialogue.

Of course the question what the proper allocation of the burden should be, is far from trivial. This makes the study of discourse rules and the consequences of these rules in dialogue games and actual legal practice all the more relevant.

\subsection{DiaLaw}

Lodder's DiaLaw is a MacKenzie-style [14] general legal dialogue game [13]. It is a two-person dialogue game implemented as a Prolog program. There is no arbiter. The program monitors the players' moves and keeps track of their commitments in a Hamblin-style [11] commitment store. The underlying logic is Reason Based Logic [8, 9, 20].

DiaLaw distinguishes four types of move: claim, accept, question, and withdraw. The moves and their consequences for the commitments of the players and the burden of argument can be summarised as follows.

Claim is used to adduce statements. A player may only claim statements to which he is not already committed. He is also not allowed to claim a sentence if he is committed to the negation of the sentence. A player who claims a sentence is committed to that sentence.

With accept, a player expresses that he accepts a sentence claimed by the other player. He thereby commits himself to the sentence. One can only accept sentences brought forward by the other player.

Question expresses doubt about a sentence adduced by the other player. It is therefore a reaction-move. When a claim is questioned, the player who adduced it has to defend it by providing a justification for the claim. The burden of proof always rests on the player who adduced the sentence. A player may ask for justification of a statement, even if he is already committed to this statement. ${ }^{2}$

\footnotetext{
${ }^{2}$ This, in my view, opens the way to an infinite regress in which the opponent questions every defence brought forward by the claimant.
} 
Withdraw allows the players to retract statements from his commitment store. It is the inverse of claim; once a claim is withdrawn, the corresponding commitment is also withdrawn.

A game in DiaLaw starts with a thesis brought forward by the proponent. The players then take turns in making moves, one move at a time. Each move is a reaction to the other player's previous move. Which moves are allowed at a certain point in the game depends on the opponent's last move and the structural rules of the game. One may, for instance, only question a claim adduced in the preceding move. The game ends either if both players are committed to the thesis, or if the proponent withdraws the thesis. These termination rules imply that dialogues in DiaLaw are not guaranteed to end. If the players fail to reach agreement, the game does not terminate. There is no arbiter to lift possible deadlocks.

There are two ways in which players become committed to statements: voluntary and forced. Voluntary commitment results from the moves claim and accept. A player can also be forced to accept a statement if the statement follows from commitments the player already has. Forced commitment is comparable to derivation in monological models.

The following dialog in natural language shows DiaLaw in action (taken from [13]).

\begin{tabular}{|l|l|l|l|}
\hline & move & Bert & Ernie \\
\hline 1 & claim & O.J. is a murderer & \\
\hline 2 & question & & Is he? \\
\hline 3 & claim & $\begin{array}{l}\text { yes, he shot his former } \\
\text { wife }\end{array}$ & \\
\hline 4 & accept & & $\begin{array}{l}\text { I think you are } \\
\text { right Bert }\end{array}$ \\
\hline & & Bert wins & \\
\hline
\end{tabular}

In move 1 Bert advances a claim that O.J. is a murderer. As a result of this claim he is committed to this fact. He bears the burden of defending the claim if the opponent challenges it, which Ernie does in move 2. In support of the thesis, Bert states that O.J. shot his former wife, which, by virtue of an unstated rule ('he who shoots a person is a murderer'), would make him a murderer. Ernie seems to be aware of the truth of this statement and accepts it as true in move 4. As a result Ernie is committed to the thesis. This commitment rests on the assumption that Ernie is committed to the rule 'he who shoots a person is a murderer' and can not challenge it.

Dialogues in DiaLaw can, of course, be far more complex than shown here. DiaLaw can handle defeasible rules, reasons and weighing of reasons, illegal moves etc. In this paper, I am interested in the burden of proof, so I will let the other topics rest.

The burden of proof in DiaLaw is relatively straightforward. The player who claims a sentence bears the burden of justification for this sentence if requested by means of the move 'question'. If the opponent requests justification of a claim, the dialogue is said to enter a sub-dialogue, which either ends in an acceptance of the challenged claim, a withdrawal of the challenged claim, or a tie. The latter means the dialogue remains in a deadlock that can not be resolved since there is no arbiter who can lift it by a binding decision. The burden of proof in DiaLaw is connected to claiming statements. This means that every counterargument leads to a switch in dialectical roles, and hence leads to a shift in the burden of proof. A counterargument has to strictly defeat the argument under attack. In the following case the burden of proof initially rests on Bert. Ernie's move shifts it to Ernie, provided Bert questions Ernie's move in his next move.

Bert: O.J. is a murderer

Ernie: O.J. is not a murderer.

\subsection{Toulmin Dialogue Game}

Bench-Capon's Toulmin Dialogue Game (TDG) [3] is a dialogue game based on the well known Toulmin argument scheme [19]. Bench-Capon's objective was to design a dialogue game that provided more expressiveness than models such as DiaLaw. The additional expressiveness stems from the fact that the Toulmin scheme allows for different roles of the premises, which gives arguments a richer structure. The Toulmin structure incorporates three important elements that make it suitable for analysing and representing legal argument. It allows for defeasible arguments, by means of rebuttals. It allows for extra logical justification, through the backing which represents the authority of the warrant (e.g. the legal source of the warrant). And finally, it allows to express the strength of the argument, by means of the qualifier; does the claim follow necessarily from the data, is it likely, or whatever.

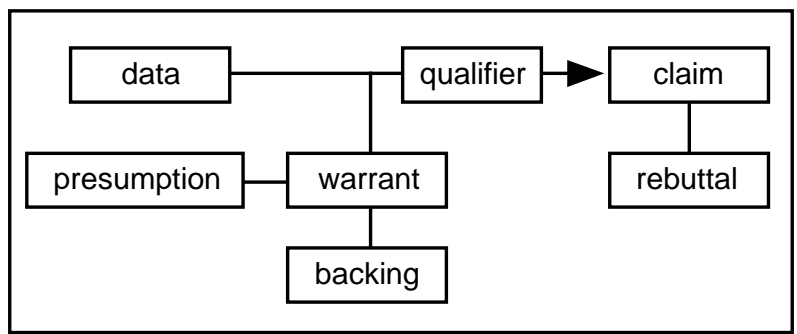

Fig. 1. (Augmented) Toulmin argument schema

Bench-Capon leaves out the qualifier in his model, and extends it with a presupposition that links to the warrant. It supposes to represent propositions assumed to be true in the context, default assumptions. They need not be discussed, but may be if the opponent requires it [3].

The fact that premises are distinguished according to their role in the argument results in more types of move (16 in total) than DiaLaw has. It also has a more elaborate system for the distribution of proof. This is a direct consequence of the richer set of moves, and the introduction of the presupposition premise.

TDG is a three party game: two players and a referee. The players have roles, proponent and opponent, that change whenever a rebuttal is issued. This results in a shift in the burden of proof, much in the way this occurs in DiaLaw as shown in the OJ sample above.

The TDG is specified as a state transition diagram and a specification of the moves in terms of their preconditions, the postconditions that specify the effects of a given move, and the completion conditions which state when a move is complete. 
Whereas DiaLaw allows an opponent to question a claim by the proponent to initiate a justification, the TDG has a richer set of move-substantiate move pairs:
P: $\operatorname{Claim}(\mathrm{C})$
$-\mathrm{P}$ asserts $\mathrm{C}$
O: Why $(\mathrm{C})$
- $\mathrm{O}$ seeks data supporting $\mathrm{C}$
O: $\mathrm{So}(\mathrm{C})$
$-\mathrm{O}$ requests the warrant for $\mathrm{C}$

After $\operatorname{Why}(C)$ or $\operatorname{So}(C)$ the proponent either has to withdraw his claim, or support his argument with data or a warrant.

P: Withdraw $(\mathrm{C}) \quad-\mathrm{P}$ withdraws his commitment to $\mathrm{C}$

P: Supply Data(C) $-\mathrm{P}$ asserts that $\mathrm{D}$ and that $\mathrm{D}$ supports $\mathrm{C}$

P: Supply Warrant(C) - P asserts If D then C

After the proponent has supplied a warrant, the opponent can request further support for the argument by asking for the presupposition or the backing of the warrant.

$\begin{array}{ll}\text { O: Presupposing }(\mathrm{C}) & -\mathrm{O} \text { requests the presupposition of } \mathrm{C} \\ \mathrm{O}: \text { On account of }(\mathrm{C}) & -\mathrm{O} \text { requests the backing for the warrant } \\ & \text { of } \mathrm{C}\end{array}$

P: Supply Presupposition(C)

$-\mathrm{P}$ asserts that $\mathrm{S}$

P: Supply Backing(C) - P says that B is the authority for his argument for $\mathrm{C}$

If the proponent withdraws a claim, control is handed to the referee, who can invite the opponent to rebut the proponent's claim, select another open claim to be the focus of the dialogue, or decide to end the dialogue.
R: Rebut?(C)
- Player is invited to rebut an implicit commitment
O/P: Rebuttal(C)
- Player provides a rebuttal, D, of C
R: Current Claim (C)
- Player is invited to either why or so a new open claim
R: End
- The referee terminates the dialogue

Basically these moves represent attacks, or probes, on all labelled premises in the augmented Toulmin structure. In each case the proponent bears the burden to prove the premise under attack, or withdraw the premise and hand over control to the referee.

An example of a dispute, part of the sample in [17] in TDG could run as follows.

\begin{tabular}{|c|c|c|}
\hline party & move & content \\
\hline alice & claim & we have a valid contract \\
\hline bob & why? & \\
\hline alice & $\begin{array}{l}\text { supply } \\
\text { data }\end{array}$ & $\begin{array}{l}\text { witnesses Smith and Baker heard you } \\
\text { accept my offer }\end{array}$ \\
\hline bob & so? & \\
\hline alice & $\begin{array}{l}\text { supply } \\
\text { warrant }\end{array}$ & offer $\&$ acceptance $\Rightarrow$ valid contract \\
\hline bob & ok & \\
\hline referee & rebut? & \\
\hline bob & rebuttal & $\begin{array}{l}\text { I was insane and the time of } \\
\text { negotiations, } \\
\text { insane } \Rightarrow \neg \text { valid contract }\end{array}$ \\
\hline alice & $\begin{array}{l}\text { on } \\
\text { account } \\
\text { of? }\end{array}$ & \\
\hline bob & $\begin{array}{l}\text { supply } \\
\text { backing }\end{array}$ & $\begin{array}{l}\text { this court's document declares me } \\
\text { insane. }\end{array}$ \\
\hline referee & rebut? & \\
\hline
\end{tabular}

\begin{tabular}{|l|l|l|}
\hline alice & ok & \\
\hline referee & end & \\
\hline
\end{tabular}

Alice claims that there is a valid contract, which bob questions. He wants to know the grounds for this conclusion, which alice gives. Bob wants to know what warrant alice wants to invoke. He can agree to the warrant provided. Because of his acceptance of the warrant, control is then passed to the referee, who asks bob if he wants to rebut alice's claim. The rebuttal introduced by bob leads to a shift in the burden of proof. According to [3] the alice now only has the choice to either ask for the presuppositions of the bob's warrant or the backing of his warrant. Bob issues a backing. Alice is committed to the warrant, unless she rebuts the warrant. From [3] it is not clear if this also means that bob's rebuttal defeats her initial claim.

In comparison to DiaLaw, TDG allows a distinction to be made between justification by argument and from authority, between presupposed context and substantive premises and claims and claims intended as a rebuttal of a previous claim. Although Bench-Capon's dialogue rules do not make a difference in commitments or consequences if a player does not live up to his burden, the differentiation in types of moves allows for distinctions to be made, which may prove useful as we will see later on.

The inclusion of a referee in the TDG also marks a difference with DiaLaw. It's task is rather straightforward in its current implementation. Control in deadlocks and after withdraw is passed to the referee. Whenever the preconditions for rebut?(C) are satisfied the referee asks the opponent if she wants to rebut an implicit commitment. If the opponent takes on this opportunity, she has to issue the rebuttal and bears the burden to substantiate it by providing data and a warrant for its support. This marks a difference with DiaLaw. Where a rebuttal (a claim -C) in DiaLaw only places a burden to prove $-\mathrm{C}$ when requested by C's proponent, TDG requires the justification to be provided directly, so even without C's proponent asking for it. The move rebut?(C) can only be issued if the player is not yet committed to $\mathrm{C}$, but is committed to both 'if D then C' and D. If the player does not take on the opportunity to rebut $\mathrm{C}$, he has to accept $\mathrm{C}$. In DiaLaw the player who is committed to both $\mathrm{D}$ and the rule 'if $\mathrm{D}$ then $\mathrm{C}$ ' is forced to accept $\mathrm{C}$, unless he provides reasons against $\mathrm{C}$. The effects are the same, but in DiaLaw, the commitment results from the discourse rules, whereas in TDG the player acknowledges his commitment to $\mathrm{C}$ explicitly. If the preconditions for rebut? are not satisfied, the referee issues a current claim move to select another open claim if there is one. This allows the player not committed to the open claim to issue a why or so move. This in effect places the burden of proof for the open claim on the player committed to the claim. If there are no open claims left, there is no option for the referee but to issue an ends move that terminates the dialogue. So, although TDG has a referee, it does not really assign the burden of proof over the players, as would sometimes be useful [16].

Bench-Capon succeeded in designing a dialogue game that is capable of representing dialogues more naturally than for instance DiaLaw does. The way the burden of proof is handled in TDG resembles that of DiaLaw. It therefore suffers from the same shortcomings. 


\subsection{Pleadings Game}

Gordon's Pleadings Game (PG) [6] aims at finding the premises about which parties in a dispute disagree and that explain their disagreement about what the outcome of their case should be [10]. It models the pleadings phase in the civil proceedings, which makes it all the more relevant for this paper. Gordon models a subset of Alexy's discourse rules [1] that have particular consequences for the burden of proof in his game. These rules as reformulated by Gordon, are:

1. No party may contradict himself.

2. A party who concedes that a rule is valid must be prepared to apply the rule to every set of objects which satisfy its antecedents.

3. An argument supporting an issue may be asserted only when the issue has been denied by the opponent.

4. A party may deny any claim, made by the opponent, if it is not a necessary consequence of his own claims.

5. A party may rebut a supporting argument for an issue he has denied.

6. A party may defeat the rebuttal of a supporting argument for one of his own claims, if the claim is an issue.

There are four types of moves in the PG:

Concede accepts an apponent's statement as true. The player that concedes a statement becomes committed to the statement.

Deny corresponds to a question move in DiaLaw, it is not a denial of a statement. Its pragmatic effect is that it requests the other party to bear his burden of proof.

Defend a claim, argument or rebuttal by an argument.

Declare a defeasible rule to be accurate. A rule in PG corresponds to a warrant in the Toulmin scheme and may have a backing.

The moves operate on statements (claim p, argument A p, rebuttal A p C, and denial s). They are guided by the (ten) dialogue rules. The opponent has to deny or concede every claim issued. Claims known to be entailed by opponent's commitments are conceded automatically.

The burden of proof is handled by the rules for the deny and the defend moves. A player may request justification for claims (and denials) not known to be entailed by his own claims by means of the deny move. By denying a denial, the player leaves any issued raised by the claim for trial and prevents the other player from supporting the claim, and from entering an infinite regress. The player who bears the burden of proof for a claim has to provide a rule (warrant), claim its validity, the facts and the rule's applicability, by means of the defend move. The defending argument must prove that the argument entails the claim under attack, but needs not prove the consistency of the argument in the current context. The proof of inconsistency lies with the opponent, who may show the inconsistency by asserting a rebuttal.

The burden of proof in PG is similar to that in DiaLaw and TDG. Players bear the burden of proof for the statements they claim, except for the introduction of rules (declare). Rules need no proof, but their backing can be questioned. Commitments are somewhat more complex than in the other games. Players have to respond to each claim by conceding or denying them. Concessions lead to commitments; the players commit themselves explicitly, as in DiaLaw and TDG. Players are also committed to the known consequences (using conditional entailment) of their statements. This resembles the forced commitments in DiaLaw. Commitments can not be retracted.

The dialogue models presented all have a fairly simple way of distributing the burden of proof over the players. In the next section I describe an actual legal procedure to show that these models are not sufficient to serve as a model for this type of legal proceedings.

\section{LEGAL ANALYSIS}

\subsection{Dutch Civil Summons Procedure}

In [12], I have given a detailed analysis of the Dutch Civil Summons Procedure (CSP in short) from the perspective of developing more realistic legal dialogue games. The CSP seemed a suitable procedure to be modelled in a dialogue game. The CSP is an example of a legal dialogue between two parties. The court in these proceedings is fairly passive. It maintains the procedure (rights and obligations of the parties) and is not involved in factfinding, as in, for instance, criminal proceedings. Maintaining the procedure is a task that can be done by a computer program [6]. The court allocates the burden of proof, determines whether claims are sufficiently grounded in the facts provided by the parties, completes the parties' arguments with legal and common knowledge, decides about admissibility of evidence, and assesses the evidence [17]. Prakken [17] provides a model in which also the task of allocating the burden of proof is accounted for to a large extent. Another reason to study this particular type of procedure is that it can be said to be purely procedural in Rawls' sense [18, 7, 12]. The court's decision in an actual case can not be determined without following the proper procedure. The decision in a case depends on the application of rules. Rule application is an action that may or may not be performed. It is not a mere logical operation. It may, for instance, be that the conditions of a rule are satisfied in a particular case, but that there are also reasons not to apply the rule, for instance because application would run against the rule's purpose. It may also be that a rule should be applied while the conditions are not satisfied (analogy). A legal case in court can only be won by actually adduced arguments, not by the mere fact that winning arguments exist in principle. Legal decisions are not logical proofs derived from legal axioms and facts of the case, but rather conclusions supported by arguments brought forward in a mediated dialogue. The arguments are based on interpretations of both the law and the facts of the case.

In principle, law and facts belong to the domain of the court and the parties respectively, as will be clear later on in the paper. In actual dialogue the parties try to place, under supervision of the court, boundary marks around the court's playground. The court's decision must be within the marks placed by the parties in the dispute.

The Dutch CSP differs significantly from civil procedures in other countries, especially from those in common-law jurisdictions. I will therefore briefly outline the procedure before going into details about the burden of proof in the CSP. 


\subsection{A bird's eye view of the procedure}

The Dutch CSP resembles the English High Court procedure. It commences with the plaintiff servicing a writ (Dutch: dagvaarding). The writ is a formal document and only needs, apart from the obligatory administrative data, to state the claim. If the defendant returns an acknowledgement of service, the pleadings begin. The pleadings are a formal exchange of documents; there is hardly ever an oral exchange of arguments. The first of these documents is the Statement of Claim (Dutch: conclusie van eis). Dutch law (Code of Civil Procedure, Dutch: Wetboek van Burgerlijke Rechtvordering) requires the Statement of Claim to provide the grounds for the claim. If the claim is not sufficiently supported by facts, the court will rule out the claim on these grounds. The defendant replies to the statement of claim with a Defence (Dutch: conclusie van antwoord). The Defence has to provide an argument rebutting the plaintiff's claim. After the Defence, the court will see if the case is fit for a hearing (Dutch: comparitie na antwoord). In this procedure, the court tries to get a clear picture of the case and it will try to reach a settlement between the parties. If the dispute does not end in a settlement during the hearings, the plaintiff may provide further support for his claim and react to the defendant's Defence by means of a Reply (Dutch: conclusie van repliek). The defendant may in turn, respond with a Rejoinder. The defendant does not need the court's consent to file a Rejoinder (which he would need in the English High Crown procedure). After the Rejoinder the parties may exchange subsequent pleadings with the court's consent.

After pleadings, the parties may bring the case to trial. In most cases, no oral pleadings will take place, but instead all documents exchanged, including proof if produced, will be handed to the court (the court's file). The court will decide the case on the basis of this file, and no new material will be brought in from the parties. This means that questions pertaining to the allocation of the burden of proof only play a role in the pleadings phase and not the trial phase. In the trial phase, the court completes the parties' arguments with well known facts, and legal grounds, keeps track of which claims have been made and their status. The court will also decide on the strength of the arguments and weigh conflicting arguments.

A dialogue model for the Civil Summons Procedure needs to have rules to represent the procedure on this (macro) level (Structural rules as they are called by Walton and Krabbe [22]). Also needed are locution, commitment and win-and-loss rules. I will now focus on the locution and commitment rules in the Dutch Civil Summons Procedure.

\subsection{Burden of Proof}

In civil summons the plaintiff seeks legal relief, such as monetary compensation for damages. This requires him to state (claim) the desired legal consequences in his Statement of Claim. In the Dutch procedure merely stating the claim does not suffice. The plaintiff has to show that his claim is tenable by presenting an argument supporting his claim. In terms of the Toulmin schema (figure 1) the plaintiff has to state the legal conclusion (claim) he wants the court to draw, as well as the necessary data to support this claim. He is not obliged to state a warrant linking the data to the conclusion. Ius curia novit, the court is supposed to know the law (art. $48 \mathrm{Rv}$ ). The court will use whatever legal rule it sees fit to decide the case. In principle, the law is the court's domain. This does, however, not mean there will be no discussion about the applicable rules. The interpretation of legal sources in respect to a particular case is one of the topics in a legal dialogue. The applicable rules and their backing will play a role in the arguments as presented by the parties. So, although the court is in no way bound by these arguments about applicable law, they nevertheless play a role in the Dutch CSP.

The fact that the plaintiff has to provide arguments supporting his claim from the outset, marks a departure from the simple rule for the burden of proof as found in DiaLaw, or the Gordon's discourse rule number three. A player is not only obliged to defend a claim when requested, but also when he presents the claim. The same goes for the defendant; he has to present arguments against the plaintiff's claim in his Defence. The formal requirement (art. 140/141 Rv) for motivated claims/attacks does not specify what level of support is required. The parties will have to try to strike a balance between offering too little and offering too much support. In the former case, the court may rule out the claim as untenable because of lack of justification. In the latter case, the proponent offers the opponent the opportunity of questioning facts he does not want to justify of prove, for instance because this proof may well fail.

\subsubsection{Sources of burden of proof}

The simple rule for the allocation of the burden of proof ('the one who makes a claim bears the burden of proof') is more complicated in the Dutch civil procedure. Article 177 of the Dutch Code of Civil Procedure states (loosely translated):

A party, who wants to invoke the legal consequences of the facts or rights adduced by her, bears the burden of proof for these facts or rights, unless any special provision or reasonableness calls for a different burden of proof.

This means that making a claim does not always constitute a burden to prove the claim. Instead of only looking at which party asserts a certain fact, the burden of proof also depends on the content of legal provisions. Dutch Civil Law is a statutory domain with the Dutch Civil Code at its core. The statutory provisions in the Dutch Civil Code, in principle, determine which side bears the burden of proof. Many of these provisions both have a substantive aspect, the rights and obligations they establish, as well as a procedural aspect, which party bears the burden of proof. Consider, for example, article 6:162 of the Dutch Civil Code (BW) (wrongful act or tort):

\section{Article $162 \mathrm{BW}^{3}$}

1. A person who commits an unlawful act towards another, which can be imputed to him, must repair the damage, which the other person suffers as a consequence thereof.

\footnotetext{
3 Translation taken from [4].
} 
2. Except where there is a ground of justification, the following acts are deemed to be unlawful: the violation of a right, an act or omission violating a statutory duty or a rule of unwritten law pertaining to proper social conduct.

3. An unlawful act can be imputed to its author if it results from his fault or from a cause for which he is answerable according to law or common opinion.

Article 6:162.1 BW states under which circumstances a plaintiff may claim compensation for damages caused by the defendant: the defendant must have committed an unlawful act, the act must be imputable on him, the plaintiff must suffer damages and the damages must have been caused by the act. The plaintiff bears the burden to prove that these conditions are met as a consequence of art. $177 \mathrm{Rv}$. If the plaintiff succeeds, the defendants behaviour counts defeasibly as unlawful. The defendant bears the burden of proof to show that an exception as stated in 6:162.2 BW applies and that therefore the plaintiff's claim is untenable. The defendant's argument is a rebuttal in terms of the Toulmin argument schema (figure one).

Article 177 of the Code of Civil Procedure contains two exceptions to the default allocation of burden of proof: special provisions and reasonableness. An example of a shift in the burden of proof due to a special provision can be seen in group-action tort cases. The Californian case Summers vs Tice et al. could serve as an example. ${ }^{4}$ Tice, Simonson and Summers are hunting. Tice and Simonson see a grouse some yards above Summers. They both fire a shot at the grouse. Unfortunately Summers gets wounded in the eye and lip by some grain of shot. Which of the two, Tice or Simonson, did cause the wounds? In order to get compensation for the damages caused by the shot, Summers would, according to article 6:162.1 BW, have to prove whether is was Tice or Simonson who fired the fatal shot. This could be too much of a burden, ending up Summers without compensation at all. The purely procedural provision article 6:99 BW sees to a shift of the burden of proof. Article 6:99 BW holds each person involved in the unlawful act responsible for the act, and hence for the repayment of the damages caused by this act. Summers only has to show that he was injured by a shot fired by Tice and/or Simonson. Tice and Simonson are both responsible. According to article 6:99 $\mathrm{BW}$, they can each lift their individual duty to repay the damages by showing their action did not cause the damages in question. This clearly shifts the burden from Summers to Tice and Simonson.

The purpose of this kind of shift in burden of proof is clear. In some cases the default burden of proof is unbearable for the one who bears it, while a shift in burden of proof would be fairer. The same applies to reasonableness as a reason to shift the default burden of proof. It is, for instance, much easier for a doctor to prove that he acted carefully and according the rules, than for a

\footnotetext{
${ }^{4}$ California Supreme Court (In Banc) - November 17, 1948 (33 Cal2d (Adv 48), 199 P2d 1, 5 ALR2d 91).
}

patient to prove that he did not. The judge may for this reason place the burden of proof on the shoulders of the doctor. ${ }^{5}$

In general, the default distribution of the burden of proof is determined by the substantive legal rules. For this reason, the text of the statutory provisions in the Dutch Civil code contains clear (at least sometimes) indications about the concrete burden of proof. Presumptions play an important role in this respect. As shown in figure 1, proof of a fact (claim) can be delivered by showing that certain grounds are present and that a warrant linking data and conclusion exists. The presence of the grounds (and the warrant) leads to the presumption that the conclusion is warranted. In the Dutch Civil Code we can distinguish between defeasible presumptions and indefeasible presumptions. In the case of an indefeasible presumption the presence of some fact is taken to imply the presence of another fact. No proof to the contrary is allowed, it therefore functions as incontrovertible evidence. Article 6:236 BW represents an indefeasible presumption: 'some clauses in standard written terms of business are unreasonable to customers (the black list)'. If a provision in a standard written terms of business is blacklisted, the producer is not allowed to show the reasonableness of the provision.

Another example of an indefeasible presumption is an affidavit. The content of a deed (of conveyance) or an affidavit enacted by the proper authorities is indefeasible. It's content can not be questioned by the opponent. Indefeasible presumptions count as conclusive evidence [17]. The only way to counter such proof is by showing that the deed or affidavit was the result of an improper procedure, for instance because it was enacted by a solicitor not sworn in. Defeasible presumptions can be defeated by proof to the contrary. Article 6:237 BW, for instance, states: 'some clauses in the standard written terms of business are deemed to be unreasonable to customers (the grey list)'. This represents a defeasible presumption. The producer can show that the clause in question is reasonable in relation to the customer. The wording of statutory provisions hints at whether a presumption is defeasible ('presumptive evidence', Dutch: wordt vermoed) or indefeasible ('deemed', Dutch: wordt geacht).

From the perspective of legal dialogue games, the fact that substantive rules hint at the burden of proof is interesting. A catalogue of the default burden of proof for the statutory provisions in the Dutch Civil Code could be used by the dialogue game to monitor and distribute the burden of proof in the dialogue game. While it is difficult for the machine to evaluate whether a player has given sufficient justification for a claim, it is possible to evaluate if a player is obliged to justify a claim at all, and within restrictions if justification is provided. See [17] for a model that incorporates an algorithm along these lines.

\footnotetext{
${ }^{5}$ In HR 20-11-1987 NJ 1988, 500, the Dutch supreme court ruled that the burden rested on the shoulders of the plaintiff (patient), but that the doctor had to supply sufficient facts to support his denial of plaintiff's claim. The burden to provide these facts was intended to provide the plaintiff with possible grounds for further arguments.
} 


\subsubsection{No burden of proof}

Not all claims have to be justified. Many dialogue games feature a type of move that allows a player to agree (or accept) a claim made by the other party. When a party accepts a claim adduced by the other party, he commits himself to this claim. Claims to which both parties are committed need not be proven or justified. Also the court is committed to these facts, even if it knows them to be false. The latter is a consequence of the principle of party autonomy in the civil procedure.

A second type of fact that needs no justification is the wellknown fact. Well-known facts, such as "trains can move fast" are true by default. The party who wants to question a well-known fact bears the burden of proof for the contrary. A complication is that the court decides if a fact is a well-known fact. The Dutch Supreme Court, for instance, held the fact that Yew-trees (in England also known by the quite appropriate name 'HorseDeath') can kill horses not to be a well-known fact. Hence, the defendant who disposed of the remains of his trimmed Yew tree where claimant's horse could eat and die from it, was under no obligation to deposit the waste elsewhere. This decision was disputed in the media as being a city-lawyer decision. It was argued that anyone with 'green fingers' knows Yew-trees to be dangerous to horses. The defendant should therefore have known this and he should have taken care of his garden waste in a more responsible manner, thereby saving the life of claimant's horse.

A third type of fact that needs no justification, is the fact that relates to the procedure itself. Whether a party filed a Defence is a question the Court can answer without resort to proof by the parties.

Finally there is a convenient closure rule in the civil procedure: Uncontested facts are considered to be true. Both parties, and the court, are committed to these uncontested facts. In actual cases the parties try to dodge this closing rule by stating that they deny all facts asserted by the opponent in every document, unless clearly accepted. This move misses its target, for obvious reasons. Some dialogue games contain a closure rule for commitments like the one outlined here (e.g. MacKenzie's dialogue game [14]). The Pleadings Game, although it is a model for the civil proceedings, does not.

A final aspect relating to the burden of proof in the Dutch Civil Procedure that I want to discuss is the request to court to be allowed to prove certain facts (article $192.1 \mathrm{Rv}$, Dutch: 'bewijsaanbod'). The court may not refuse the requestor this opportunity. In a sense the offer to prove a fact is a questioning of one's own move to be certain that one is given the opportunity to justify a fact in the case the opponent does not ask for justification. It is a sort of self-referential move. An offer to prove is usually made if an expert witness is probable to corroborate a fact asserted by the proponent, while the opponent is likely not to call for the expert witness to testify.

This concludes the brief description of the CSP and burden of proof in the civil procedure. It is far from complete, but I hope it shows that an analysis of legal discourse from a legal perspective brings out relevant topics for dialogue game designers to tackle.

\section{DISCUSSION}

General legal dialog games such as the ones discussed do insufficient justice to the essential characteristics of actual legal procedures. The study of the Dutch Civil Summons Procedure shows where refinements in current dialog games can be made.

In DiaLaw, the TDG and the Pleadings Game burden of proof depends on commitments. A player can only be asked to provide proof for statements to which he is committed. The CSP, and $[16,17]$, however, show that the judge may also place a burden of proof (for the contrary) on the opponent, and hence on a party not who is not committed to it. The games discussed can not handle this kind of burden allocation. DiaLaw and the Pleadings Game do not have a referee and the role of the referee in TDG is too limited. But even if we restrict the burden of proof to statements to which a player is committed, actual practice is more complicated than represented in the games discussed. There are several ways in which a party can become committed to a statement, not all resulting in a burden of proof. A party may explicitly accept a statement asserted by the other party (Dutch: gerechtelijke erkentenis, article $181 \mathrm{Rv}$ ) and hence become committed to it. This move corresponds to the moves accept in DiaLaw, $O K$ in TDG and concede in PG. This kind of commitment differs from a commitment resulting from a claim; it is unlikely that the player who explicitly accepts a statement can be asked to offer justification for the statement. An even weaker form of commitment results from the fact that the parties are committed to the statements they don't question or attack, due to the closure rule (uncontested facts are taken to be true). This type of implicit commitment is temporary in the sense that the statement can be challenged later on. None of the models discussed can handle implicit acceptance well. In the Pleadings Game and TDG parties have to either accept or deny/question a statement and hence implicit commitment does not exist in these games,

Also with regard to the move claim more can be said on the basis of the analysis of the CSP. Not every fact asserted by a party leads to the same type of commitment and possibly associated burden of proof. Well-known facts don't carry a burden of proof, while assertions about rights ordinarily do. The discussion in the previous section showed distinct types of claims and the associated burden. There unfortunately is no clear cut border between the various types. The consequences for the burden of proof depend on the content of claims. DiaLaw can not distinguish propositions on their content or role in the dialogue and hence has to treat all propositions alike. It would not help to have wellknown facts in the commitment stores of the players before starting the game, because then no player can question them or rebut them. In TDG a distinction can be made because they can be labeled according to their role in the argument. TDG could therefore assign different levels of proof required to rebut the various statements and types of statements. A distinction made by Freeman and Farley [5] can be of help here. They distinguish five levels of support for a claim, ranging from scintilla of evidence, where there is at least one defensible argument for the claim, to beyond a doubt, where there is at least one valid, defensible argument for the claim, and where all arguments of the opponent for the opposite claim are defeated. Presuppositions, such as well- 
known facts and other defaults, can be labeled as such and treated accordingly when attacked. The various level of proof induce different protocols. Scintilla of evidence, for instance, requires all counterarguments of the defendant to be strictly defeating, while the arguments of the plaintiff can be merely defeating [16]. Another option would be to enrich the role of the referee, as is done in [17].

Another improvement of the existing systems can be found in enriching the types of move for claims. Walton and Krabbe [22], for instance, distinguish between assertions, which carry a burden of proof, versus mere concessions, which may be made for the sake of argument and do not have a burden of proof attached. Distinctions such as these open the way to richer dialogue structures.

In DiaLaw we have seen that claiming the opposite of a proponent's claim leads to a shift in the burden of proof (the OJ example). In the Dutch CSP there would not be no such shift (see also [16, 17]). The Dutch supreme court ruled that article $177 \mathrm{Rv}$ does not imply that a defendant has to provide proof for the facts adduced to question the facts asserted by the proponent (HR 23 Oct 1992, NJ 1992, 813). This gives rise to make a distinction in the question move. It makes sense to distinguish between:

- Asking for justification of a statement. This is the question move in DiaLaw (deny in PG).

- Requesting clarification. This should not impose a burden of proof on the other player

- Asking whether a player is serious about a fact, and hence is prepared to justify or defend the fact, but without actually imposing the burden.

- Denying a fact. This is a counter attack, which may (or may not) cause the burden of proof to shift.

- Confronting the other player with an inconsistency in his argument and hence a request to resolve this inconsistency.

\section{CONCLUSION}

Commitment and burden of proof are difficult concepts that lie at the core of legal dialog games. The proper handling of both depends on the dialogue moves and the dialogue rules. In this paper I have tried to show that simple dialogue games such as DiaLaw do not do justice to actual legal procedures. Both the types of moves and the dialogue rules can be refined on the basis of the analysis of an actual legal procedure. Steps towards more realistic dialogue games include the construction of a typology of locutions that cover the relevant aspects of legal dialogues. Work done by Gordon [6], Lodder [13], Walton and Krabbe [22], Bench-Capon [3], myself [12], and others can be combined for this purpose. Another useful enterprise, for a model of the Dutch civil procedure at least, is the construction of an encyclopaedia containing the default distribution of the burden of proof for each statutory provision. A moderator can use this knowledge base to monitor the dialogue. Another topic that needs much work, is the rule-set for the dialogue game. I have argued that the distribution of the burden of proof in the civil summons procedure consists of a system of rules and exceptions. These rules and exceptions will have to be transformed into dialogue rules. A further complication is that in the actual procedure, these rules only represent the default situation. In principle everything is open to discussion in legal discourse, also the rules of the procedure itself. The dialogue game therefore also needs to be able to cope with changes in the discourse rules of the game. This need was already acknowledged by Lodder [13]. Vreeswijk [21] has recently pursued research along this line. A final promising line of research is taken on by Prakken $[16,17]$ who tries to model the judge's role in dialogue games on the basis of analysis similar to the one carried out in this paper.

Legal dialogue games offer a promising way to study legal argument. In legal discourse, at least in principle, everything can be disputed. This does not mean that the outcome of the dialogue is completely at the disposal of the parties in the dispute. Both the law and the judge play an important role in limiting the discretion of the parties in the dispute. The role of the law in the summons procedure as described in this paper, is twofold: it plays a substantial role and a procedural role. In my view the challenge for researchers in the field of legal computational dialectics is to devise models that take as much from the procedural aspects of law into account to construct models that make realistic debates about the substantial aspect of legal rules possible.

\section{ACKNOWLEDGMENTS}

I would like to thank Henry Prakken and Jaap Hage for their comments on an earlier version of this paper.

\section{REFERENCES}

[1] R. Alexy. A Theory of Legal Argumentation; The Theory of Rational Legal Discourse as Theory of Legal Justification. Oxford: Clarendon Press, 1989.

[2] T.J.M. Bench-Capon. Argument in Artificial Intelligence and Law. In J.C. Hage, T.J.M. Bench-Capon, M.J. Cohen, H.J. van den Herik (eds.) Legal knowledge based systems JURIX '95: Telecommunication and AI \& Law. Lelystad: Koninklijke Vermande, 5-14, 1995.

[3] T.J.M. Bench-Capon. Specification and Implementation of Toulmin Dialogue Game. In J.C. Hage, T.J.M. Bench-Capon, A.W. Koers, C.N.J. de Vey Mestdagh, C.A.F.M. Grütters (eds) Jurix 1998: Jurix: The Eleventh Conference. Nijmegen: Gerard Noodt Instituut, 5-20, 1998.

[4] G. Betlem. Civil Liability for Transfrontier Pollution. London: Graham and Trotman, 1993.

[5] K. Freeman and A.M. Farley. A Model of Argumentation and Its Application to Legal Reasoning. Artificial Intelligence and Law, 4:163-197, 1996.

[6] T.F. Gordon. The Pleadings Game: An excercise in computational dialectics. Artificial Intelligence and Law, 2:239-292, 1994.

[7] Jaap C. Hage, Ronald Leenes and Arno R. Lodder. Hard cases: a procedural approach. Artificial Intelligence and Law, 2:113-166, 1994. 
[8] Jaap C. Hage. A Model of Legal Reasoning and a Logic to Match. Artificial Intelligence and Law, 4 nos. 3-4:199-273, 1996.

[9] Jaap C. Hage. Reasoning with rules. Dordrecht: Kluwer Academic Publishers, 1997.

[10] Jaap C. Hage. Dialectical Models in Artificial Intelligence and Law. Artificial Intelligence and Law, vol 8 no 2-3, 137$172,2000$.

[11] C.L. Hamblin. Fallacies. London: Methuen, 1970.

[12] Ronald E. Leenes. Hercules of Karneades, Hard cases in recht en rechtsinformatica. (Hercules of Karneades, Hard cases in Law and AI and Law), PhD thesis University of Twente, Enschede: Twente University Press, 1998 (in Dutch).

[13] Arno R. Lodder. DiaLaw: On legal justification and dialog games. Boston, Mass.: Kluwer Academic Publishers, 1999.

[14] J.D. Mackenzie. Question-Begging in Non-Cumulative Systems. Journal of Philosophical Logic, 8:159-177, 1979.

[15] Henry Prakken and Giovanni Sartor, Modelling Reasoning with Precedents in a Formal Dialogue Game. Artificial Intelligence and Law, 6:231-287, 1998.
[16] Henry Prakken. On Formalising Burden of Proof in Legal Argument. In H. Jaap van den Herik et al. (eds), Legal Knowledge Based Systems, JURIX 1999, The Twelfth Conference, Nijmegen: GNI, 85-97, 1999.

[17] Henry Prakken. Modelling Reasoning about Evidence in Legal Procedures. In Proceedings of the Eighth International Conference on Artificial Intelligence and Law, (this volume), 2001.

[18] J. Rawls. A theory of Justice. Oxford: Oxford University Press, 1972.

[19] S.E. Toulmin. The uses of argument. Cambridge: Cambridge University Press, 1958.

[20] Bart Verheij. Rules, Reasons, Arguments. Formal studies of argumentation and defeat. $\mathrm{PhD}$-thesis Maastricht University, 1996.

[21] Gerard A.W. Vreeswijk. Representation of Formal Dispute with a Standing Order. Artificial Intelligence and Law, 8 nos. 2-3:205-231, 2000.

[22] D.N. Walton and E.C.W. Krabbe. Commitment in Dialogue; Basic Concepts of Interpersonal Reasoning. New York: State University of New York Press, 1995. 